\title{
Representações das categorias cognitivas e sua diacronia Interface Linguística cognitiva - Linguística histórica
}

RESUMO: A partir dos anos 80 do século passado, a Linguística histórica voltou a ocupar a atenção dos linguistas brasileiros. O objetivo deste trabalho é identificar novos rumos na pesquisa diacrônica. Para isso, dividi o texto em três secções: momentos da Linguística histórica, sistemas complexos e Linguística histórica, representação da categoria de MOVIMENTO na história da língua portuguesa. Nas conclusões, propõe-se que o Princípio de projeção reúne todas as manifestações linguísticas de MOVIMENTO.

Palavras-chave: Linguística histórica. Linguística Cognitiva. História do Português brasileiro. Representações da categoria de MOVIMENTO no Português europeu e no Português brasileiro.

\begin{abstract}
Since the nineteen-eighties onwards, Historical Linguistics has been given fresh attention by Brazilian linguists. This text aims to point out new trends in current diachronic research. To this end, the text is divided into three sections: key theoretical developments in Historical Linguistics, complex systems and Historical Linguistics, the representation of the cognitive category мотіом in the history of the Portuguese language. In the conclusion, a Principle of projection has been proposed in order to put together different manifestations of MOTION.
\end{abstract}

Keywords: Historical Linguistics. Cognitive Linguistics. History of Brazilian Portuguese. Representations of the category of MOTION in both European and Brazilian Portuguese.

\section{Apresentação}

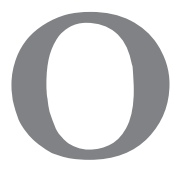

objetivo deste trabalho é examinar a interface Linguística histórica / Linguística cognitiva, investigando as representações da categoria de MOVIMENTO, para verificar se por esse meio poderemos explicar algumas das diferenças entre o Português brasileiro e o Português europeu.

Universidade de São Paulo, Universidade Estadual de Campinas, CNPq. 
O trabalho tem três partes: (1) três momentos da Linguística Histórica, (2) sistemas complexos e Linguística Histórica, (3) representações da categoria de MOVIMENTO no PE e no $\mathrm{PB}$.

1. Três momentos da Linguística histórica

A Linguística moderna surgiu com a Linguística Histórica, no começo do séc. XIX. Suas primeiras publicações recebiam o título de "gramática histórica". Essa direção de estudos desenvolveu várias teorias sobre a mudança linguística. Vou concentrar-me em apenas três: (1) neogramáticos e a centralidade da Fonética, (2) estruturalistas e a centralidade da Fonologia, (3) funcionalistas e a centralidade do uso.

\subsection{Os neogramáticos e a centralidade da Fonética}

Os neogramáticos se concentraram na história das línguas previamente afiliadas pelos comparatistas. De certa forma, eles retomaram as atividades da Filologia Clássica, atacada pelos comparatistas, concentrando-se na gramática dessas línguas - o que lhes valeu o apelido de "neogramáticos".

A teoria dos neogramáticos foi sistematizada por Herman Paul, num trabalho de 1880, reformulado na edição de 1920. Seu livro transformou-se num dos clássicos da Linguística: Paul (1880 / 1920 / 1970). Essa teoria assenta nos seguintes princípios:

(1) O historiador de uma língua natural tem como tarefa de base acompanhar as diversas fases ou diversos estados da língua, entendida como um "organismo psíquico", ou mental, como diríamos hoje. Esse organismo é uma sorte de gramática internalizada, e dela decorrem os enunciados; tais enunciados são elementos relacionados uns com os outros.

(2) As relações linguísticas são perceptíveis na fala individual, o que permite lançar uma ponte entre a pesquisa linguística e a pesquisa psicológica. Mas é necessário relacionar os usos individuais com os usos coletivos, para melhor entender o mecanismo da mudança linguística. $\mathrm{O}$ uso coletivo não passa de um artefato do linguista: (i) Não há limites entre usos coletivos, que serão idealmente concebidos como uma soma de usos individuais. (ii) A única realidade disponível é o uso individual, e é nesse nível de consideração que as mudanças são desencadeadas, sobretudo quando usos são acrescentados ou 
subtraídos ao uso coletivo. (iii) Dois mecanismos causam as mudanças no uso individual: a) a mudança espontânea, explicável pelas tensões sintagmáticas, isto é, pela acomodação de um som ao que lhe está contíguo na cadeia da fala, e b) as adaptações da fala individual a outra fala individual, o que pressupõe o intercurso verbal como um momento importante na mudança.

(3) O momento decisivo da mudança linguística está, portanto, localizado no uso individual. Paul (1880/1920/1970) afirma que tal mudança se dá por meio de "passos infinitesimais", um dos quais é o princípio do "maior conforto [articulatório]", expressão que se tornou conhecida entre nós como "lei do mínimo esforço", acaso uma versão infeliz da denominação original. Sendo foneticamente gradual, a mudança "avança por uma implementação imperceptivel, mas lexicalmente abrupta, afetando simultaneamente todas as palavras relevantes", na leitura de Labov (1981). Os difusionistas aduziriam evidências contrárias a esta posição: Oliveira $(1991,2003)$.

Há duas decorrências deste princípio, as quais foram sendo fixadas ao longo da Linguística histórica portuguesa de inspiração neogramatical: (i) Como as mudanças fonéticas se fundamentam na produção fisiológica dos sons, elas têm certa universalidade e espontaneidade. Mesmo em línguas muito diversas entre si podemos encontrar o mesmo tipo de mudança, dado que tudo é uma questão de acomodações entre sons contíguos, produzidos por um "aparelho fonador" em si mesmo idêntico. (ii) As mudanças fonéticas, por isso mesmo, não admitem exceções, e os casos de irregularidade decorrem de empréstimos linguísticos, ou de analogias. Ou, como reconheciam Brugman Osthoff (1878), apud Paul (1880 / 1920 / 1986), "cada mudança fônica, visto que ocorre mecanicamente, tem lugar de acordo com leis que não admitem exceşão".

(4) A mudança não tem um ritmo permanente, e conforma-se à estabilidade maior ou menor dos usos individuais. Historiadores das ideias linguísticas vêm nisto uma evidência de que Herman Paul admitia o acaso como um fator de mudança. De todo modo, o curso de uma mudança passa pela difusão de um novo hábito de uma minoria para uma maioria, o que levanta a questão das mudanças intra e intergeracionais, que viria a ser tematizada pela Teoria da variação e mudança. Paul quer com isto dizer que um "fato novo" pode ser melhor identificado pelo adulto do que pela criança, mais suscetível de captar e executar as tendências à mudança, identificáveis em sua "gramática implícita". 
(5) Somente os fatores fonéticos podem condicionar a mudança. Isto quer dizer que os neogramáticos aparentemente não incluíam em sua argumentação fatores de caráter morfológico ou sintático. Os fatores fonéticos podem ser sistematizados em termos de assimilação, dissimilação, permuta, adição, apagamento, transposição e outros. No caso do apagamento de sons, a perda das consoantes travadoras de sílaba teve consequências morfológicas importantes no sistema do Português, quando essas consoantes funcionam como morfemas, como o caso de $\{\mathrm{s}\}$ marcador de plural.

As afirmações dos neogramáticos foram fortemente acolhidas nas "gramáticas históricas do Português", que organizaram os fatores fonéticos, impulsionando este momento da Linguística histórica: Pereira (1915/1933), Nunes (1919/1945), Leite de Vasconcelos (1911 / 1926 / 1988), Hüber (1933/1986), Lima Coutinho (1938/1958). Toda uma geração de linguistas brasileiros foi formada nestas fontes, nos anos cinquenta do século XX, quando a Linguística histórica ocupava o centro das estruturas curriculares dos cursos de Letras. Têm o maior destaque, aqui, os trabalhos que Theodoro Henrique Maurer Jr. desenvolveu na USP: Maurer Jr. (1959, 1962).

Essas ideias voltaram a ser discutidas nos últimos anos, com refutações muito fortes, criando-se a chamada "controvérsia neogramatical", que parece resumir se nisto: o que realmente muda, o som ou a palavra? Sobre isto, ver Labov (1981 e 1995).

1.2. Os estruturalistas: a centralidade da Fonologia

O Estruturalismo se constitui numa "família teórica" que tem em comum postular a língua como um sistema constituído por subsistemas hierarquicamente dispostos.

A cada subsistema correponde uma unidade, formalmente designada por vocábulos técnicos terminados em -ema.

Os estruturalistas concentraram na Fonologia o motor da mudança linguística. Martinet (1955) estipulou três processos de mudança fonológica:

1) Fonologização: é o surgimento de um fonema novo, a partir da criação de um traço pertinente inexistente no estágio linguístico anterior. Assim, no quadro das vogais latino-vulgares, não se estabeleciam dois graus na abertura 
média. O Português criou o traço pertinente /+ média aberta/, surgindo as$\operatorname{sim} \mathrm{o} / \varepsilon / \mathrm{e} / \mathrm{\rho}$. Analogamente, o Latim vulgar não tinha o traço /+ palatal/ em seu quadro de consoantes. O Português, e outras línguas românicas, criaram esse traço, enriquecendo-se o quadro respectivo, em nosso caso, com os fonemas palatais $/ \check{s} /,|\check{z} /,| \tilde{n} /, / \lambda /$. Vogais médias abertas e consoantes palatais são casos de fonologização.

2) Transfonologização: é o surgimento de um fonema novo, mediante o aproveitamento de um traço pertinente já existente no sistema. A extensão do traço / + sonoro/ deu surgimento, no Português, aos fonemas consonantais $/ v / e / z /$. A transfonologização promove o equilíbrio do sistema fonológico, preenchendo as "casas vazias" deixadas pelo não aproveitamento integral de um traço pertinente.

3) Desfonologização: é a perda de um traço, e consequente desaparecimento de fonemas. O Português perdeu o traço de quantidade e, por consequência, não temos vogais nem consoantes longas com valor fonológico, que desempenhavam um papel importante no sistema fonológico latino-vulgar, preservado em grande parte pelo Italiano.

Essas ideias foram examinadas no Português por Câmara Jr. (1975), Borba (1972), Zággari (1988), Mattos e Silva (1991, 1993).

Adaptando o esquema de Martinet para a Morfologia Diacrônica, podese afirmar que na passagem do Latim Vulgar para o Português houve casos de morfologização (criação dos morfonemas, formação dos tempos compostos e das perífrases verbais, criação de novos morfemas para o futuro do presente e do pretérito) e de desmorfologização (desaparecimento dos casos, perda nos substantivos, do futuro imperfeito do indicativo, do imperfeito do subjuntivo, dos particípios presente e futuro, desaparecimento dos morfemas de grau dos Adjetivos). Seriam casos de transmorfologização a recategorização de formas compostas da passiva perifrástica.

Sobre a morfologia diacrônica do Português, v. Câmara Jr. (1975), Naro (1973), Maia (1986), Mattos e Silva (1991, 1993, 2008).

$\mathrm{Na}$ mesma linha do raciocínio estruturalista, as alterações morfológicas implicariam em alterações sintáticas. Assim,

1. A perda das consoantes travadoras de sílabas, tanto quanto dos casos na morfologia nominal, desencadearam (i) o rearranjo na marcação do plural, com a 
migração dos marcadores para a posição pré-núcleo, (ii) a expansão do uso das preposições, e (iii) certo enrijecimento da ordem de figuração dos constituintes sentenciais, tornando-se o Português progressivamente uma língua configuracional.

2. No PB, estamos observando agora a destruição do sistema casual dos pronomes, e suas consequências na expressão das categorias funcionais de sujeito e de objeto direto.

3. As alterações já mencionadas na morfologia verbal, tais como (i) a simplificação do quadro conjugacional, reduzido a três formas, com consequência na retenção do sujeito, (ii) o desaparecimento do particípio presente e sua substituição pelo gerúndio, o declínio no uso dessa forma e do infinitivo, ocasionaram uma utilização mais frequente das conjunções, no caso das sentenças encaixadas.

Para uma abordagem estruturalista da sintaxe diacrônica do Português, v. Mattos e Silva (1989).

1.3. Os funcionalistas e os sociolinguistas: a centralidade do uso

Sapir (1921/1954) afirmava que o fenômeno da variação linguística acarreta o da mudança: se há duas ou mais formas em competição, uma delas acabará por vencer a outra. Essa ideia foi elaborada por William Labov, que a denominou Teoria da variação e mudança. Seu objetivo maior é apanhar a mudança "em seu pleno voo", por assim dizer.

No texto fundacional dessa teoria, Weinreich-Labov-Herzog (1968) começam por destacar as inconveniências do ponto de vista estruturalista e gerativista sobre a mudança. Uma e outra teoria postulam que a língua é homogênea, e praticada por um falante ideal, o que vai complicar seriamente as coisas tanto no plano sincrônico da descrição linguística, quanto no plano diacrônico de interpretação de sua mudança. Fixando a atenção neste último aspecto, esses linguistas reclamam que

\footnotetext{
quanto mais os linguistas se impressionarem com a existência da estrutura da língua, quanto mais apoiarem esta observação em argumentos dedutivos a respeito das vantagens funcionais da estrutura, tanto mais misteriosa se tornará a transição de um estágio para outro dessa mesma língua. Afinal de contas, se uma língua tem de ser estruturada para funcionar eficientemente, como as pessoas continuarão a falar enquanto a língua muda, isto é, enquanto ela passa por períodos de uma sistematicidade atenuada? Weinreich/Labov/ Herzog (1968), p. 100.
} 
Para dar resposta a estas e a outras questões, os sociolinguistas formularam a Teoria da variação e mudança, na qual eles propõem "quebrar a identificação entre estruturação e homogeneidade", e ir ao encalço da competência linguística dos falantes, a qual está ancorada numa heterogeneidade sistematizada, pois a "ausência da heterogeneidade estruturada seria disfuncional". A ancoragem da mudança nos usos da linguagem traz os sociolinguistas labovianos para o campo do Funcionalismo.

Os seguintes argumentos compõem a Teoria variacionista da mudança:

1) Reconhece-se a existência de princípios restritivos que governam a mudança de determinada estrutura. Há uma covariação entre esses princípios e variações individuais, as quais devem ser definidas: Weinreich/Labov/Herzog (1968: 101 e 170).

2) A mudança das estruturas põe o problema da transição, isto é, há estágios intermediários nessa mudança, os quais podem ser empiricamente observados e controlados. Para examinar a transição será necessário determinar o valor da variável linguística, pois "uma mudança linguística pode ocorrer numa gradação discreta" (ibidem, pág. 170).

3) Duas questões resultam daqui: (i) questão do encaixamento: como as mudanças se encaixam "na matriz dos concomitantes linguísticos e extralinguisticos das formas em questão?", isto é, por que setores da estrutura linguística a mudança tem começo, e que segmentos da sociedade a incorporam primeiramente? (ii) questão da avaliação: como as mudanças são avaliadas em termos de seu impacto sobre a estrutura linguística e sobre a eficiência comunicativa? (págs. 101 e 181). A avaliação pode acelerar ou bloquear uma mudança, segundo ela seja ou não aceita pelas classes sociais de mais prestígio.

4) Mas a questão mais central a respeito da mudança é a de sua implementação: que fatores a favorecem? por que certas línguas dotadas do mesmo traço estrutural não passam pela mesma mudança?

5) Um dos aspectos mais notáveis da Teoria da variação e mudança já mencionados, é o fato de que podemos observar a mudança linguística no tempo real. A esse respeito, Naro / Scherre (1993) dão o seguinte exemplo:

“o estado atual da língua de um falante adulto reflete o estado da língua adquirida quando o falante tinha aproximadamente quinze anos de idade. Assim sendo, a fala de uma pessoa com sessenta hoje representa a língua de quarenta anos atrás, enquanto outra pessoa com quarenta anos hoje revela a língua de há apenas vinte e cinco anos". 
Esse mesmo autor agrega que nem todas as variáveis são sujeitas à mudança. Há na língua setores mais estáveis, e que prosseguem com vitalidade, mesmo que sujeitos ao fenômeno da variação (pág. 84).

As aplicações da Teoria da variação e mudança ao PB têm sido muito extensas, destacando-se as pesquisas de Fernando Tarallo e Mary A. Kato na Universidade Estadual de Campinas, que promoveram o casamento dessa teoria com a teoria gerativista, os estudos sobre a fala popular de Rodrigues (1987) na Universidade de São Paulo, e a vasta produção do Projeto censo linguístico, atual Projeto de estudo dos usos linguísticos, com sede na Universidade Federal do Rio de Janeiro.

No quadro das teorias funcionalistas da mudança, hipotetizei que seu momento crucial ocorre nos atos conversacionais. Quando mais heterogênea é a comunidade, tanto maior será o esforço aplicado à manutenção da conversação - e a língua acelera sua mudança. Inversamente, quando mais homogênea, menor será esse esforço - e a língua diminui seu ritmo de mudança: Castilho (2000).

\section{Sistemas complexos e Linguística histórica}

Os três momentos teóricos acima compartilham pontos comuns sobre a pesquisa diacrônica:

(1) Aceitam a representação da língua como um conjunto hierarquizado de categorias.

(2) Localizam seu objeto empírico à volta da Fonética, da Fonologia, da Morfologia e da Sintaxe - ou seja, da Gramática - deixando num segundo plano os outros sistemas linguísticos: o Léxico, a Semântica e o Discurso. Apenas os variacionistas introduziram fatores semânticos e discursivos em suas pesquisas.

(3) Adotam os princípios das ciências clássicas como base epistemológica de suas pesquisas.

As seguintes afirmações configuram a ciência clássica:

1. Os fenômenos encontrados na natureza são desordenados e confusos, ocultando sua regularidade.

2. Para assegurar alguns resultados e conclusões, temos de considerar os dados em sua estatividade.

3. Os sistemas identificados pela abordagem clássica têm uma grande elegância conceptual e uma notável simplicidade analítica. 
4. O caminho para a descoberta cientifica é maiormente dedutivo. Cada situação é traduzida em termos matemáticos, um modelo é construido, e de agora em diante as ocorrências serão explicadas de acordo com esse modelo.

Não comentarei aqui cada um desses princípios, o que fiz em Castilho (2007). Mas o fato é que, aplicados à língua falada, eles não deram certo, pois não conseguiram revelar o tremendo dinamismo de que a língua é feita. Muita coisa teria de ser varrida para debaixo do tapete, com o carimbo de aberrante. Creio que sua continuada aplicação ao campo da pesquisa diacrônica levará ao mesmo ponto. Daí a necessidade de se procurar outra perspectiva epistemológica para nossas pesquisas.

A ciência clássica funciona bem na descrição e história de produtos cristalizados. O problema é que tanto a descrição da oralidade quanto a investigação diacrônica focalizam maiormente os processos linguísticos.

Para adequar a teoria a essa empiria, precisaremos operar com a ciência dos sistemas complexos.

As seguintes afirmações configuram os sistemas complexos:

1. Os componentes dos sistemas complexos exibem um tipo de ordem sem periodicidade, em fluxo contínuo, em mudança - como queria Heráclito.

2. Os sistemas não são lineares, são dinâmicos, exibem um comportamento irregular, imprevisivel.

3. Os elementos dos sistemas complexos exibem relacionamentos simultâneos, não são construídos passo a passo, linearmente. Eles são adaptáveis e auto-organizados.

4. As anomalias identificadas pela abordagem clássica exemplificam fenômenos vitais para 0 entendimento do problema, e não deveriam ser descartadas como aberrantes.

5. Uma nova topologia do impreciso, do vago, do aproximativo, precisará ser proposta.

6. A competição nos sistemas é mais importante que sua consistência.

7. Finalmente, ao tratar de fenômenos complexos, nenbum método revelará por si mesmo o objeto por inteiro.

Como estabelecer um diálogo entre a Linguística histórica e a percepção dos sistemas complexos acima definida? Isso já tem ocorrido na Meteorologia, na Economia, na Psicologia, cujos objetos empíricos são imprevisíveis, dinâmicos, de difícil modelização: Gleick (1988), Waldrop (1993), Cilliers (2000). Em nosso país, a Linguística estava ficando de lado dessa perspectiva, até que surgiu a coletânea de ensaios publicada por Paiva e Nascimento (orgs. 2009). Anteriormente, eu tinha publicado um texto programático: Castilho (2007). 
Para encaminhar o debate, e postular a língua como um sistema dinâmico e complexo, precisaremos aceitar as seguintes premissas:

(1) Do ângulo de sua produção, as línguas serão definiveis como um conjunto de processos mentais, pré-verbais, organizáveis num multissistema operacional.

Os processos que organizam as línguas entendidas em seu dinamismo operam (i) simultaneamente, não sequencialmente, (ii) dinamicamente (não são entidades estáticas), (iii) multilinearmente (não são entidades unilineares).

Esses processos podem ser razoavelmente articulados e concentrados em quatro domínios: (1) lexicalização, (2), discursivização, (3) semanticização e (4) gramaticalização.

Ainda que timidamente, os estudos sobre a gramaticalização levantaram o véu da língua-enquanto-processo. Entretanto, esses estudos não conseguiram enquadrar a gramaticalização entre os outros processos de criação linguística, optando, antes, por uma obscuredora abordagem epifenomênica: Castilho (2004).

(2) Do ângulo de seus produtos, as linguas serão apresentadas como um conjunto de categorias igualmente organizadas num multissistema.

A língua-enquanto-produto é um conjunto de categorias agrupadas ao mesmo tempo em quatro sistemas: (1) Léxico, (2) Discurso, (3) Semântica (4) Gramática.

Esses sistemas serão considerados autônomos uns em relação aos outros, ou seja, não se admitirá que um derive de outro, nem se proporá uma hierarquia entre eles, rejeitando-se as relações de determinação, comuns na literatura disponível. Em consequência, não se postulará a existência de sistemas centrais e de sistemas periféricos, mencionados rapidamente na seção 1 , acima. Admitiremos que qualquer expressão linguística exibe ao mesmo tempo características lexicais, discursivas, semânticas e gramaticais. É disso que as línguas naturais são feitas.

Seja como conjunto de processos, seja como conjunto de produtos, todos eles ordenados nos quatro sistemas, a língua depende de uma articulação intersistêmica, que assegure a eficácia de seu uso. Proponho que essa articulação se dá através do Princípio sociocognitivo de ativação, reativação e 
desativação de propriedades lexicais, semânticas, discursivas e gramaticais. Esse princípio tem seu fundamento nas estratégias da conversação: Castilho (1998/ 2004).

A lexicalização, a semanticização, a discursivização e a gramaticalização poderiam constituir-se, portanto, em novas áreas da Linguística histórica, no quadro da teoria dos sistemas complexos. E como é impossível dominar individualmente todos esses processos, fica patente que eles têm de ser estudados por equipes, inviabilizando-se o trabalho solitário. Os projetos coletivos que tão bem distinguem a Linguística brasileira deixam de lado, nesta perspectiva, seu espontaneísmo, tornando-se necessidades imperiosas, sem o que será impossível, por exemplo, produzir um conhecimento articulado sobre a história do Português Brasileiro.

No período mais forte da atuação do Estruturalismo e do Gerativismo, movimentos basicamente a-históricos, a Linguística histórica passou para o segundo plano. Chegou-se mesmo a anunciar sua morte, dado o impacto das teorias descritivistas, que favorecem o estudo de uma dada sincronia.

É verdade, entretanto, que mesmo em seu interior algumas vozes anunciavam a volta da "velha senhora". Lembrem-se as pesquisas de A. Martinet sobre a Fonologia diacrônica, no quadro do Estruturalismo, e a teoria dos Princípios e parâmetros de N. Chomsky, no quadro do Gerativismo. No Brasil, foi profética a voz de Fernando Tarallo, que proclamou o renascimento da "fênix", excelente metáfora para uma ciência que retorna sempre: Tarallo (1984).

Nos anos 80 , sem que tivesse havido uma combinação prévia, três respeitáveis linguistas fizeram renascer a Linguística histórica no domínio da língua portuguesa: Maia (1986), na Universidade de Coimbra, com seus estudos sobre o Galego-Português, Mattos e Silva (1989), na Universidade Federal da Bahia, com seu estudo sobre o Português trecentista, a que se seguiu o Programa de História do Português, e Mary Kato, na Universidade Estadual de Campinas, juntamente com Fernando Tarallo, que promoveram o casamento entre variacionismo e gerativismo: Kato / Tarallo (1989); sobre os principais resultados desta vertente, ver Roberts / Kato (Orgs. 1993).

Todas estas questões repercutiram no Programa de Pós-Graduação em Filologia e Língua Portuguesa da Universidade de São Paulo, que decidiu em 1997 historiar o Português de São Paulo. Foi então realizado o I Seminário do Projeto para a História do Português Paulista, logo transformado em Projeto 
para a História do Português Brasileiro (PHPB). Atualmente, onze equipes regionais integram o $\mathrm{PHPB}$, de que se indica o coordenador, entre parênteses: Alagoas (Denilda Moura), Bahia (Tânia Lobo), Ceará (Aurea Suely Zavam), Minas Gerais (Jânia Ramos), Paraíba (Camilo Rosa), Paraná (Vanderci Aguilera), Pernambuco (Valéria Gomes), Rio de Janeiro (Dinah M. I. Callou), Rio Grande do Norte (Marco Antônio Martins), Santa Catarina (Izete L. Coelho), São Paulo (Ataliba T. de Castilho)

A equipe paulista do PHPB se reorganizou em 2007, tendo elaborado um plano de ações para o período de 2007 a 2010. Batizada de "Projeto Caipira", a atividade foi financiada durante esse período pela Fapesp, na modalidade "projeto temático de equipe" (proc. 06/55944-0). Cerca de 60 pesquisadores se articularam a partir de dez subprojetos, de que resultaram em curto espaço de tempo muitas dissertações e teses, além de três coletâneas de ensaios: Castilho (org. 2009), Torres-Morais e Andrade (orgs. 2009), LimaHernandes e Santiago Almeida (orgs. no prelo). Outros materiais serão publicados oportunamente. O presente texto se situa entre as atividades do PHPB/ SP.

\section{As categorias cognitivas e suas representações}

Acredito que a Linguística histórica poderia abrigar uma nova linha de pesquisas, incluindo em sua agenda indagações como aquelas contidas no item (1) acima, aqui repetido: do ângulo de sua producão, as linguas serão definiveis como um conjunto de processos mentais, pré-verbais, organizáveis num multissistema operacional.

A Linguística cognitiva poderá nos ajudar na caracterização desses processos mentais. Para isso, tomarei como aceite que essa disciplina (i) estuda as representações de categorias cognitivas tais como PESSOA, COISA, ESPAÇO E TEMPO, MOVIMENTO, QUALIDADE, QUANTIDADE, entre outras, sempre mediadas por sua interpretação cultural, (ii) as categorias cognitivas são problemáticas, no sentido de que elas são integrativas, não negativas, ocorrendo em nossas mentes simultaneamente, não linearmente, e, por fim, (iii) os processos mentais correspondem às categorias e às suas representações.

Com respeito a (i), sabe-se que a Linguística cognitiva é definida na literatura pelo que ela não é, como nesta afirmação de Silva (1997: 61), segundo quem essa direção de estudos não aceita 
(a) "a existência de um nível estrutural (...) no significado linguístico (...) distinto do nível no qual o conhecimento do mundo é associado às formas linguísticas; (b) a arbitrariedade do signo linguístico; (c) a postulação de que as categorias linguísticas são discretas e homogêneas; (d) a aceitação de que a língua é gerada por regras lógicas e por traços semânticos objetivos; (e) a autonomia e a motivação não semântica da sintaxe".

Mais tarde, Talmy (2000/2001: 2-3) afirmou que

"The relatively recent tradition of cognitive linguistics has centered itself within [the conceptual approach of language]. It has thus addressed the structuring within language of such basic conceptual categories as those of space and time, scenes and events, entities and processes, motion and location, force and causation"

Com respeito a (ii), focalizarei a atenção na categoria de MOVIMENTO. Como uma categoria problemática, o MOVIMENTO captura as entidades em seu dinamismo. Quando capturamos essas entidades no seu movimento verídico, temos o MOVIMENTO FACTIVO. Quando as capturamos em seu movimento não verídico, temos o MOVIMENTO FICTício.

Talmy (2000/2001: 100-105) observa que o que é concebido como um MOVIMENTO FICTÍCIO é "an entity or the observation of an entity" (ênfase acrescentada). Esta afirmação dispõe o MOVIMENTO no sistema mais amplo da VISÃo, como pode ser visto da página $160 \mathrm{em}$ seguida. Como já se disse aqui, as categorias cognitivas são problemáticas, não excludentes.

Uma enorme quantidade de objetos é encontrável na literatura sobre MOVIMENTO. Não pretendo entrar nesse debate. Restrinjo-me, por ora, à distinção acima, formulada por Talmy, tentando explicar por esse meio alguns problemas de mudança linguística da língua portuguesa.

Pesquisas desenvolvidas nos últimos 30 anos têm mostrado as diferenças entre o português europeu (PE) e o português brasileiro (PB). Em Castilho (2010: 192-193), recolhi grande parte dessas diferenças: 
Quadro 1 - Diferenças entre o português brasileiro e o português europeu

\begin{tabular}{|c|c|}
\hline PORTUGUÊS BRASILEIRO & PORTUGUÊS EUROPEU \\
\hline \multicolumn{2}{|c|}{ FONÉTICA E FONOLOGIA } \\
\hline $\begin{array}{l}\text { Há } 7 \text { vogais tônicas: /a/, /e/, / } /, / \mathrm{i} /, / \\
\mathrm{o} /, / \mathrm{o} /, / \mathrm{u} / \text {. Não se distingue a vogal } \\
\text { temática }\{-\mathrm{a}-\} \text { no presente e no pretérito: } \\
\text { falamos. A vogal }[\mathrm{e}] \text { se mantém como } \\
\text { anterior média fechada antes de palatal: } \\
\text { espelho, fecho. }\end{array}$ & $\begin{array}{l}\text { Há } 8 \text { vogais tônicas: /a/, /ä/, /e/, / / /, } \\
/ \text { i/, /o/, //, /u/, distinguindo-se um /a/ } \\
\text { central baixo no presente, falamos, de um /ä/ } \\
\text { mais alteado no pretérito, falämus. A vogal [e] } \\
\text { antes de palatal é dita [â]: espelho [išpâlhu], fecho } \\
\text { [fâšu]. }\end{array}$ \\
\hline $\begin{array}{l}\text { Há } 5 \text { vogais átonas pretônicas, e todas soam } \\
\text { claramente: /a/, /e/,/i/, /o/, /u/. Todas } \\
\text { elas são pronunciadas, e assim não se } \\
\text { confunde de frente com diferente. Nessa } \\
\text { distribuição, não há distinção entre [e] } \\
\text { fechado e }[\varepsilon] \text { aberto, e por isso } \\
\text { pronunciam-se da mesma forma pregar um } \\
\text { prego e pregar na igreja. }\end{array}$ & $\begin{array}{l}\text { Há } 8 \text { vogais átonas pretônicas, em que [e] } \\
\text { fechado move-se para [ë], como em pëqueno, } \\
\text { mas a tendência é omiti-las, como em telefone } \\
\text { [tulfòn], pedido [p'didu] etc. Pedir num hotel } \\
\text { um apartamento de frente será entendido como } \\
\text { "um apartamento diferente". Nessa } \\
\text { distribuição, distingue-se [e] de [E], e por isso } \\
\text { pronunciam-se diferentemente prêgar um prego } \\
\text { e prègar na igreja. }\end{array}$ \\
\hline $\begin{array}{l}\text { Há } 3 \text { vogais átonas finais: /a/, /i/, /u/, os } \\
\text { dois últimos escritos com e, o: pata, pede, peço. }\end{array}$ & Há 3 vogais átonas finais: /ä/, /e/, /u/. \\
\hline $\begin{array}{l}\text { O ditongo oral ey pode manter-se ou } \\
\text { monotongar-se (terreiru/terrêru) e o ditongo } \\
\text { nasal } \sim \text { ey mantém-se, como em bem, dito } \\
\text { [bẽy]. }\end{array}$ & $\begin{array}{l}\text { Esses ditongos soam como [äy] e [ãy]: terreiro } \\
\text { [t'rräyru], bem [bãy]. }\end{array}$ \\
\hline $\begin{array}{l}\text { Ditonga-se a vogal final seguida de } \\
\text { sibilante: } \ln \text { [ ['luys], atrás [a'trays]. }\end{array}$ & Não há essa ditongação. \\
\hline $\begin{array}{l}\text { Sílabas terminadas por oclusiva recebem } \\
\text { uma vogal, transformando-se em sílabas } \\
\text { abertas: adevogado, abissoluto, pissicologia. }\end{array}$ & $\begin{array}{l}\text { Essas sílabas soam fechadas: advogado, absoluto, } \\
\text { psicologia. }\end{array}$ \\
\hline $\begin{array}{l}\text { Pronuncia-se da mesma forma a consoante } \\
\text { [-1] e a semivogal [-w] em posição final: o } \\
\text { advérbio mal e o adjetivo mau são } \\
\text { pronunciados da mesma maneira. }\end{array}$ & $\begin{array}{l}\text { O [-1] é lateralizado, como no PB do Rio } \\
\text { Grande do Sul, não se confundindo com a } \\
\text { semivogal }[-\mathrm{w}] \text {. }\end{array}$ \\
\hline $\begin{array}{l}\text { O }[\mathrm{r}] \text { pode ser vibrante simples (caro), } \\
\text { vibrante múltipla anterior (carro), vibrante } \\
\text { múltipla posterior }[\text { káRu] ou velar surda } \\
\text { [káxu]. }\end{array}$ & $\begin{array}{l}\text { Predomina a vibrante múltipla anterior, como } \\
\text { no espanhol. }\end{array}$ \\
\hline
\end{tabular}




\begin{tabular}{|c|c|}
\hline \multicolumn{2}{|c|}{ MORFOLOGIA } \\
\hline $\begin{array}{l}\text { Simplifica-se a morfologia nominal, com a } \\
\text { perda de }\{-s\} \text { indicador de plural na variedade } \\
\text { popular, menos no Especificador, e indicador } \\
\text { de pessoa, na morfologia verbal, em que a } \\
\text { pessoa } t u \text { foi substituída por você. }\end{array}$ & $\begin{array}{l}\text { A morfologia nominal e verbal não } \\
\text { apresentam essas simplificações, exceto em } \\
\text { alguns falares. regionais. }\end{array}$ \\
\hline $\begin{array}{l}\text { O quadro dos pronomes pessoais tônicos } \\
\text { apresenta quatro formas: eu/você/ele/ nós, que } \\
\text { alterna com a gente/eles. A morfologia verbal } \\
\text { acompanha essa simplificação, reduzindo-se } \\
\text { a } 4 \text { formas: falo, fala, falamos, falam. Em } \\
\text { consequência, mudarão as regras de } \\
\text { concordância do verbo com o sujeito. }\end{array}$ & $\begin{array}{l}\text { O quadro dos pronomes pessoais tônicos } \\
\text { apresenta seis formas: eu/tu/ele/nós/vós/eles. } \\
\text { A morfologia verbal dispõe de } 6 \text { formas } \\
\text { diferentes: falo, falas, fala, falamos, falais, falam. }\end{array}$ \\
\hline $\begin{array}{l}\text { O quadro dos pronomes pessoais átonos (ou } \\
\text { clíticos) apresenta duas formas: me, te, nos, } \\
\text { tendendo a desaparecer (i) o acusativo o: } \\
\text { Ainda não vi Ø hoje, (ii) o acusativo te, } \\
\text { substituído por para você: Preciso falar uma coisa } \\
\text { pra você, e (iii) o reflexivo se, que se generaliza } \\
\text { como reflexivo universal, no PB popular: Nos } \\
\text { nossos dias não Ø usa mais saia, Eu não se alembro. }\end{array}$ & $\begin{array}{l}\text { O quadro dos pronomes pessoais átonos } \\
\text { apresenta seis formas: } m e, t e, s e / s i \text {, nos, vos. O } \\
\text { reflexivo si pode se referir ao interlocutor: } \\
\text { isto épara si. }\end{array}$ \\
\hline \multicolumn{2}{|c|}{ SINTAXE } \\
\hline $\begin{array}{l}\text { No tratamento, usa-se você quando há } \\
\text { intimidade, e o senhor nas situações formais. } \\
\text { Essa forma continua a alterar-se, surgindo ocê } \\
\text { e cê. Nas regiões em que se mantém tu no } \\
\text { tratamento informal, o pronome você marca } \\
\text { certo distanciamento. }\end{array}$ & $\begin{array}{l}\text { Até o século XVI, usava-se } t u \text { para o tratamento } \\
\text { informal e vós para o tratamento formal. Vós } \\
\text { era substituído por Vossa Mercê para dirigir- } \\
\text { se ao rei, depois aos nobres (e aí o rei passou } \\
\text { a ser tratado por Vossa Majestade, Vossa } \\
\text { Alteza). Vossa Mercê foi em seguida aplicado } \\
\text { ao tratamento cerimonioso da burguesia, } \\
\text { vindo finalmente a concorrer com tu, } \\
\text { mudando para você. }\end{array}$ \\
\hline $\begin{array}{l}\text { O pronome ele pode funcionar (i) como } \\
\text { objeto direto: Maria viu ela, (ii) redobrar uma } \\
\text { construção de tópico: A Maria, ela ainda não } \\
\text { chegou, (iii) aparecer na oração relativa } \\
\text { copiadora: O menino que ele chegou (veja 9.2.2). }\end{array}$ & $\begin{array}{l}\text { Ele só funciona como sujeito, o objeto direto } \\
\text { pronominal é expresso por } o \text {, não existem } \\
\text { construções de tópico nem relativas } \\
\text { copiadoras. }\end{array}$ \\
\hline 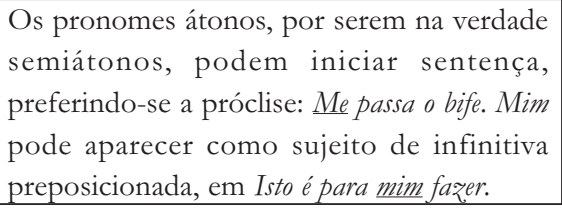 & $\begin{array}{l}\text { Os pronomes átonos não podem iniciar } \\
\text { sentença, preferindo-se a ênclise: Passa-me o } \\
\text { bife. O sujeito da infinitiva preposicionada } \\
\text { vem no caso reto: Isto é para eu faz̧er. }\end{array}$ \\
\hline
\end{tabular}




\begin{tabular}{|l|l|}
\hline $\begin{array}{l}\text { Usa-se ter em lugar de haver nas construções } \\
\text { existenciais: Hoje não tem comida. }\end{array}$ & $\begin{array}{l}\text { Usa-se apenas haver nas construções } \\
\text { existenciais: Hoje não há comida. }\end{array}$ \\
\hline $\begin{array}{l}\text { Verbos de movimento são construídos com } \\
\text { a preposição em: Vou na feira. }\end{array}$ & $\begin{array}{l}\text { Verbos de movimento são construídos com } \\
\text { a preposição a: Vou à feira. }\end{array}$ \\
\hline Ocorre a negação dupla: não sei, não. & Prefere-se a negação simples: não sei. \\
\hline $\begin{array}{l}\text { Amplia-se o uso das perífrases estar + } \\
\text { gerúndio e ir + infinitivo, substituindo neste } \\
\text { caso a forma do futuro do presente: estou } \\
\text { falando, vou falar. }\end{array}$ & $\begin{array}{l}\text { Prefere-se a perífrase estar }+ \text { a }+ \text { infinitivo, } \\
\text { mais recente que a anterior: estou a falar. A } \\
\text { forma simples do futuro é vivaz. }\end{array}$ \\
\hline $\begin{array}{l}\text { Preenche-se o lugar de sujeito e elide-se o } \\
\text { objeto direto: Ele já viu Ø. O sujeito elíptico } \\
\text { é interpretado como um participante } \\
\text { indeterminado: usa saia quer dizer "alguém } \\
\text { usa saia". }\end{array}$ & $\begin{array}{l}\text { Elide-se o sujeito e preenche-se o lugar do } \\
\text { objeto direto com o clítico o: } \varnothing \text { já o viu. O } \\
\text { participante determinado: usa saía quer } \\
\text { dizer "determinada pessoa usa saia". }\end{array}$ \\
\hline $\begin{array}{l}\text { O sujeito vem anteposto ao verbo, e o } \\
\text { objeto direto, posposto: Maria comeu o } \\
\text { chocolate. O objeto direto pode ser deslocado } \\
\text { para a esquerda, sem retomada por um } \\
\text { clítico: O chocolate, Maria comeu. }\end{array}$ & $\begin{array}{l}\text { O sujeito pode vir posposto ao verbo e o } \\
\text { objeto direto pode ser deslocado para } \\
\text { esquerda, com retomada por um clítico: O } \\
\text { chocolate, comeu-o Maria. }\end{array}$ \\
\hline
\end{tabular}

Partindo da abordagem multissistêmica da língua, vou agora considerar essas diferenças a partir de suas representações da categoria de MOVIMENTO, tomando por referência o quadro acima.

3.1. Movimento factivo

O movimento factivo é representado pelos seguintes fenômenos:

\subsubsection{No Léxico}

Os seguintes itens lexicais, entre muitos outros, representam o movimento factivo:

1. Verbos como ir, vir, deixar no sentido de afastar-se (Silva 1999: 173), etc.

2. Substantivos deverbais como ida, vinda, afastamento, etc.

3. Preposições como de, desde, a, para. 


\subsubsection{Na Gramática}

3.1.2.1. Na Fonologia, essa categoria é representada pelo movimento de fonemas, como o [r], nos casos de metátese (pergunto / pregunto) e de hipértese (Beatriz / Breatiz).

3.1.2.2. Na Morfologia, o movimento factivo é documentado na movimentação física de morfemas, como ocorre no PB pop essas coisarada bonito (Amaral 1920/1982: 48), os menino bonito (Scherre 1988, Moraes de Castilho 2009, entre outros), o morfema nominal de plural $\{\mathrm{s}\}$ moveu-se da direita para a esquerda, abandonando o núcleo do sintagma nominal $(\mathrm{SN})$, fixando-se no determinante, contribuindo assim para a tendência a deslocar as marcações gramaticais para a posição pré-núcleo. Esse movimento factivo não ocorre quando o núcleo do SN inicia-se por vogal, como em as orelhas, os olhos, situação em que o morfema nominal de plural $\{s\}$, mais propriamente, seu alomorfe $\{-z\}$, dá origem à forma PB pop zoreia, zoio.

Da mesma forma, o PB mostra uma tendência a mover seus marcadores gramaticais pós-nucleares para a posição pré-nuclear, fixando-se aí. Esse fenômeno ocorre por alterações do estatuto gramatical de verbos auxiliares, de pronomes pessoais e de verbos da sentença matriz, como nos seguintes exemplos:

(1) Modalidade: quepará (< quer parar), popará (< pode parar),

(2) Temporalidade: vopará ( $<$ vou parar),

(3) Aspectualidade: tafalanu (< está falando"), tafaladu (< está falado),

(4) Pessoa do verbo, mantendo-se os sufixos originais: ofalei $(<$ eu fale $)$, cefalô $(<$ você falou), eifalo (< ele falou), etc.

(5) Alguns verbos da sentença matriz se desgarram da sentença complexa, isolando-se à sua esquerda, dando origem a um novo marcador discursivo, como em disque < dizem que: "Disque ['diski] esse candidato ganhará as próximas eleições", ach'que < acho que: "Ach'que ['aSki] vai faltar luz".

O movimento factivo aí ilustrado é ainda pouco perceptível, pois o núcleo da expressão alterada segue retendo sua marcação sufixal. É previsível que essa marcação desapareça, por redundante, tornando-se mais forte o movimento da direita para a esquerda das formas alteradas, como anotamos em nos exemplos (1-5). Aparentemente, o PE padrão não mostra esses movimentos factivos para a esquerda.

3.1.2.3. Na Sintaxe, o MOVIMENTO FACTIVO é representado pela deslocação de constituintes, como:

i. Os clíticos se deslocam habitualmente pela sentença, mas sua movimentação não coincide nas duas modalidades. A cliticização fonológica difere no 
PE e no PB. No PE, o movimento do clítico vai da direita para a esquerda, como em

(6) PE Quem-me vê, Não-te vi, Já-te digo.

No PB, o movimento do clítico é da esquerda para a direita, como em

(7) Quem me-vê, Não te-vi, Já te-digo".

De acordo com Salvi (1990), o PE atingiu o máximo de sua procliticidade entre 1550-1600, tornando-se enclítico desde então. Pagotto (1992, 1993) mostrou que o PB experimentou uma procliticidade estável, mantendo o padrão herdado do PE no séc. XVI.

ii. No PB, o sujeito "leve", ou seja, aquele expresso por um SN simples, com menos de 7 sílabas, ocorre habitualmente antes do verbo. O sujeito "pesado", expresso por um SN complexo, com mais de 7 sílabas, movimenta-se para a direita, ocorrendo após o verbo: Castilho (2010: 290-293):

(8)

a) Então você coloca o calcáreo no caminhão.

b) Funciona mal aquele negócio de ficar perguntando tudo.

iii. O objeto direto ocorre habitualmente após o verbo, como em ( 9 a). Objetos cujo referente já é conhecido na situação discursiva, e objetos preenchidos por pronome demonstrativo neutro, movimentam-se ambos para a esquerda do verbo, como em (9b):

(9)

a) Loc 1 - Procure o livro, por favor, não consigo achá-lo.

b)

Loc 2 - Esse livro eu não procuro não.

Isso eu não faço,

Nota-se que a movimentação de sujeitos e de objetos toma direções diferentes, fortalecendo-se a diferença entre essas funções. 


\subsection{Movimento fictício}

O MOVIMENTO FICTícIO não pode ser representado tão claramente como o MOVIMENTO FACTIVO, como poderemos ver nesta secção. Trata-se aqui de deslocamentos mentais, cuja visibilidade precisa ser postulada.

O que notamos agora são traços que decolam de suas bases, que permanecem intactas, voando para todo lado, contribuindo assim para a criação de expressões verbais.

Vejamos alguns desses traços "voadores".

\subsubsection{Movimento fictício na GRAMÁTICA}

Os neogramáticos interpretavam os movimentos fictícios na Gramática como casos de analogia, em que alguma aproximação psicológica era efetivada.

3.2.1.1. Na Fonologia, um traço fonêmico se desloca de um item para outro, como a nasalidade de não, que aterrissou em assim < ad sic. A mesma palavra assim nasalou-se de novo, em ansim, agora por um movimento factivo do traço de nasalidade.

3.2.1.2. Na Morfologia, o morfema verbal da $2^{\mathrm{a}}$. pessoa do singular $\{-\mathrm{s}\}$ moveu-se ficticiamente para seu alomorfe $\{$-ste $\}$, dando origem a $\{$-stes $\}$, como em $t u$ fostes, th viestes. A $2^{a}$. pessoa do plural não deixou por menos, reafirmando sua individualidade por meio da forma $\{$-steis $\}$, como em vós fôsteis, vós viésteis, mantendo-se assim a diferença entre a 2 a. pessoa do singular e a $2^{a}$ pessoa do plural.

3.2.1.3. Na Sintaxe, o movimento fictício é mais conhecido como transitividade, quando propriedades lexicais decolam do predicador, aterrissando em seu escopo, produzindo sintagmas e sentenças.

Há diferenças entre o PE e o PB quando examinamos a transitividade de verbos de movimento. No PE esses verbos selecionam a preposição a para indicar o ALVO, como em:

(14) Vou ao cinema.

No PB, esses verbos selecionam a preposição em, para o mesmo papel temático, como em:

(15) Vou no cinema. 
Aparentemente, a escolha das preposições $a$ e em aponta para diferentes percepções de ALVO. Entre os falantes do PE padrão, o ALVO parece ser visto como um ponto próximo ao continente, ou seja, próximo àquele espaço real ou imaginário que abriga o conteúdo. Entre os falantes do PB, o ALVO é visto como um ponto dentro do continente.

\subsubsection{Movimento fictício no DISCURSO}

Para construir um texto, um tópico projeta-se ficticiamente da situação discursiva. Ele é emoldurado e reemoldurado por meio da repetição e da paráfrase, e até mesmo temporariamente posto à parte por meio de parentetizações e digressões, com o surgimento de novos tópicos. Os temas se movimentam ficticiamente pelo texto, enquanto a conversação é mantida ou enquanto um texto está em processo de ser escrito.

Para aprofundar esta secção, peço que se leia Jubran / Koch (orgs. 2006).

\subsubsection{Movimento fictício na SEMÂNTICA}

Quando criamos os sentidos, vários movimentos fictícios são operados simultaneamente: organizamos o campo visual selecionando seus participantes e os eventos em que eles estão envolvidos. Participantes e eventos são dispostos numa perspectiva de figura ou de fundo, criando-se uma hierarquia entre eles. Novos participantes e novos eventos são acrescidos por meio da inferência, da pressuposição e comparação. Nossa perspectiva dos participantes e dos eventos pode ser alterada por meio da metáfora, da metonímia, da especialização, da generalização. Vamos nos fixar na metonímia e na metáfora.

Tanto a metonímia quanto a metáfora resultam de traços semânticos que se movimentam ficticiamente.

A metonímia é a alteração semântica produzida pela movimentação de traços provenientes de uma palavra adjacente. Ela opera, portanto, com traços in praesentia. Assim, o advérbio de comparação mais é usado habitualmente em contexto de negação redobrada, como em 
(16) Não quero mais comida.

O traço negativo da palavra não movimentou-se ficticiamente para a direita, habilitando o advérbio a ser usado como a conjunção adversativa mas. Como se sabe, essa conjunção nega expectativas, como em

(17) Sua comida está boa, mas hoje vou comer fora.

O movimento do traço de negação foi fictício porque a palavra não manteve esse traço. Nos movimentos factivos, a palavra "doadora" perde o traço que foi movido.

A metáfora é a alteração semântica produzida pela movimentação de traços provenientes de uma associação cognitiva. Ela opera, portanto, com traços in absentia. Quando dizemos

(18) Nossa vida nos levou longe,

a palavra vida recebeu factivamente de levou o traço de /mobilidade/, o que permite associá-la ficticiamente a um barco, a um avião, a um pau de arara, o que quer que seja que se move, donde as metáforas

a) Nossa vida é um barco / um avião / um pau de arara.

b) Embarquei na minha vida, destemido das borrascas / das panes / dos pneus furados.

Sendo uma palavra que remete a um conceito invisível, abstrato, vida passou a representar um referente visível, concreto, como um barco. Agora, essa palavra remete a uma entidade que se move através do espaço e do tempo. Como se pode verificar, por trás das metáforas há uma comparação não expressa gramaticalmente.

Conclusões e algumas generalizações

Fica patente que tanto o $\mathrm{PE}$ quanto o $\mathrm{PB}$ não podem ser associados à seleção de uma única direção do movimento. O jogo das representações é mais sutil.

Assim, o que se nota é que, quando o PB contemporâneo adota uma MOVIMENTAÇÃO FACTIVA da direita para a esquerda, como na marcação grama- 
tical pré-nucleo, o PE não aceita essa direção. Inversamente, quando o PB adota uma movimentação da esquerda para a direita, como no caso dos clíticos, o PE igualmente refuta essa deslocação, tomando o caminho oposto.

Quanto ao MOVIMENTO FICTício, as diferentes estratégias de inferência no PE e no PB, aqui não examinadas, merecem mais atenção, para que possamos ir além das piadas que ouvimos a seu respeito nessas duas modalidades.

Em suma, além das diferenças lexicais e gramaticais entre as duas modalidades, há também diferenças cognitivas que merecem a atenção dos pesquisadores.

Poderíamos agora elaborar algumas generalizações sobre as representações da categoria de MOVIMENTO, mesmo considerando-se o caráter bastante esquemático deste texto, e o muito que ainda há a pesquisar.

Em primeiro lugar, seria possível inferir algum princípio geral por trás das representações da categoria de MOVIMENTO?

Vou propor que o Princípio de projeção reúne tais representações. Tomarei aqui o termo projeção em seu sentido comum de língua: (i) "ato ou efeito de arremessar, jogar algo para algum lugar"; (ii) "calcular antecipadamente uma situação futura"; (iii) "perceber um objeto mental como algo espacial e sensivelmente objetivo".

Retomando a percepção da língua como um multissistema, pode-se postular que o Princípio de projeção é documentado nas seguintes situações linguísticas:

1. Para manter uma conversação, prevemos a próxima atuação do interlocutor, preparando-nos para lançar nosso turno, o que já foi explicado por Sacks / Schegloff / Jefferson (1974/2003). Em Castilho (1998/2004) denominei a isto "princípio discursivo de projeção".

2. Para construir uma sentença, escolhemos um predicador, que seleciona seus argumentos, lançando sobre eles casos e papéis temáticos, dispondo-os numa dada ordem no enunciado, conectando-os, numa língua como a portuguesa, pelas regras de concordância. Este é o bem conhecido "princípio gramatical de projeção".

3. Para construir o significado, selecionamos vários traços semânticos, pondo-os em movimento, criando assim as categorias semânticas principais, como a dêixis, a referência, a predicação, tanto quanto as alterações a que submetemos os representantes dessas categorias, via metonímia e metáfora. Este será tomado como o "princípio semântico de projeção". 
Em segundo lugar, por que o PE e o PB padrão começaram a se distanciar, sobretudo a partir dos anos 1950s? Várias explicações, sobretudo de cunho social, têm sido oferecidas na literatura. Ora, talvez devêssemos operar também com argumentos cognitivos, caso em que as diferenças seriam mais profundas. Esta é a proposta deste texto. Além do mais, se as representações linguísticas do MOVIMENTO no PE e no PB parecem divergir, o que se passará, então, com as representações das outras categorias cognitivas?

\section{Referências bibliográficas}

BORBA, Francisco da Silva (1972/1973) Esboço de fonologia diacrônica. Alfa 18/19: 245274, 1972-1973.

CÂMARA Jr., Joaquim Mattoso (1975) História e estrutura da lingua portuguesa. Rio de Janeiro: Livraria Acadêmica.

CASTILHO, Ataliba T. de (1998 / 2004) A lingua falada no ensino de português. São Paulo: Contexto; 6a. ed., 2004.

CASTILHO, Ataliba T. de (2000) Para um programa de pesquisas sobre a história social do português de São Paulo. Em: R. V. Mattos e Silva (Org. 2001, tomo 2). Para a história do português brasileiro. São Paulo: Humanitas, 2 tomos, pp. 337-370.

CASTILHO, Ataliba T. de (2004) Reflexões sobre a teoria da gramaticalização. Contribuição ao debate sobre gramaticalização no contexto do PHPB. Em: Wolf Dietrich / Volker Noll (Orgs. 2004). O Português do Brasil. Perspectivas da pesquisa atual. Frankfurt am Main / Madrid: Vervuert / Iberoamericana, pp. 203-230.

CASTILHO, Ataliba T. de (2007) Abordagem da língua como um sistema complexo. Contribuições para uma nova Lingüística Histórica. Em: A.T. de Castilho / M.A. Torres Morais / R.E.V. Lopes / S.M.L. Cyrino (Orgs. 2007). Descrição, bistória e aquisição do português brasileiro. Homenagem a Mary A. Kato. Campinas: Pontes / Fapesp, pp. 329-360.

CASTILHO, Ataliba T. de (Org. 2009) História do português paulista. Série Estudos, vol. 1. Campinas: Instituto de Estudos da Linguagem, Unicamp.

CILLIERS, Paul (2000) Complexity \& postmodernism. Understanding complex systems. London and New York: Routledge.

GLEICK, James (1988) Chaos. Making a new science. New York: Penguin Books.

HÜBER, Joseph (1933 / 1986) Altportugiesches Elementarbuch. Heidelberg: Carl Winters Universitätsbuchhandlung. Gramática do português arcaico. Lisboa: Gulbenkian, tradução portuguesa, 1986.

JUBRAN, Clélia Cândida Spinardi / KOCH, Ingedore Grunfeld Villaça Koch (Orgs. 2006) Gramática do Português Culto Falado no Brasil, vol. I, Construção do texto falado. Campinas: Editora da Unicamp.

LABOV, William (1981) Field methods of the project on linguistic change and variation. Austin: Southwest Educational Development Laboratory.

LABOV, William (1995) Principles of linguistic change. Vol. 1: Internal Factors. Oxford \& Cambridge: Blackwell. 
LEITE DE VASCONCELOS, José (1911/1926/1988) Estudos de filologia portuguesa, $3^{\text {a }}$. edição. Rio de Janeiro: Livros de Portugal, 1988, com prefácio de Serafim da Silva Neto.

LIMA COUTINHO, Ismael de (1938/1958) Pontos de Gramática Histórica. Rio de Janeiro: Livraria Acadêmica, 4 ${ }^{a}$. edição revista e aumentada, 1958.

LIMA-HERNANDES, Maria Célia / ALMEIDA, Manoel Mourivaldo Santiago (orgs. no prelo) História do Português Paulista, série Ensaios, vol. 3. São Paulo: Editora da Universidade de São Paulo / Fapesp.

MAIA, Clarinda de Azevedo (1986) História do galego-português. Estudo lingüistico da Galiza e do noroeste de Portugal desde o século XIII ao século XVI. Coimbra: Instituto Nacional de Investigação Científica.

MARTINET, André (1955) Économie des changements phonétiques. Berne: A. Francke.

MATTOS E SILVA, Rosa Virgínia (1989) Estruturas trecentistas: elementos para uma gramática do português arcaico. Lisboa: Imprensa Nacional / Casa da Moeda.

MATTOS E SILVA, Rosa Virgínia (1991) Português arcaico: fonologia. São Paulo: Contexto.

MATTOS E SILVA, Rosa Virgínia (1993) Português arcaico: morfologia e sintaxe. São Paulo: Contexto.

MATTOS E SILVA, Rosa Virgínia (2008) O Português arcaico. Uma aproximação. Lisboa: Imprensa Nacional - Casa da Moeda, 2 volumes.

MAURER Jr., Theodoro Henrique (1959) Gramática do latim vulgar. Rio de Janeiro: Acadêmica. MAURER Jr., Theodoro Henrique (1962) O problema do latim vulgar. Rio de Janeiro: Livraria Acadêmica.

NARO, Anthony J. (1973) Estudos diacrônicos. Petrópolis: Vozes.

NARO, Anthony J. / SCHERRE, Marta M.P. (1993) Sobre as origens do português popular do Brasil. D.E.L.T.A. 9: 437-454, 1993.

NUNES, José Joaquim (1919 / 1945) Compêndio de gramática histórica portuguesa. Lisboa: Livraria Clássica Editora.

OLIVEIRA, Marco Antonio de (1991). The Neogrammarian Controversy Revisited. International Journal of Sociology of Language. Berlin - Alemanha, v. 89, no. 1: 93-105, 1991.

OLIVEIRA, Marco Antonio de (2003). A controvérsia neogramática reconsiderada. Em: E. Albano / S. Possenti / T. Alkmim (orgs. 2003). Saudades da Lingua. Campinas: Mercado de Letras, pp. 606-620.

PAGOTTO, Emílio G. (1992) A posição dos clíticos em Português: um estudo diacrônico. Campinas: Universidade Estadual de Campinas, Dissertação de mestrado.

PAGOTTO, Emílio G. (1993) Clíticos, mudança e seleção natural. Em: I. Roberts / M. Kato (Orgs.1993: 185-206).

PAIVA, Vera Lúcia Menezes de Oliveira e / NASCIMENTO, Mílton do (orgs. 2009) Sistemas adaptativos complexos. Lingua(gem) e aprendizagem. Belo Horizonte: Faculdade de Letras da UFMG. PAUL, Herman (1880/1920/1970) Princípios fundamentais da bistória da lingua. Lisboa: Fundação Calouste Gulbenkian, tradução de Maria Luisa Schemann.

PEREIRA, Eduardo Carlos (1915/1933) Grammatica histórica. São Paulo: Companhia Editora Nacional.

ROBERTS, Ian / KATO, Mary Aizawa (Orgs. 1993) Português brasileiro. Uma viagem diacrônica. Campinas: Editora da Unicamp. 
RODRIGUES, Ângela Cecília de Souza (1987) A concordância verbal no português popular em São Paulo. São Paulo: Universidade de São Paulo, tese de doutoramento.

SACKS, Harvey / SCHEGLOFF, Emmanuel / JEFFERSON, Gail (1974/2003) A symplest systematics for the organization of turn-taking for conversation. Language 50: 696-735, 1974. Tradução para o português: Sistemática elementar para a organização da tomada de turnos para a conversa. Veredas. Revista de Estudos Linguísticos 7 (1), 2003: 9-73, 2003.

SALVI, Giampaolo (1990) La sopravvivenza della legge di Wackernagel nei dialetti occidentali della Penisola Iberica. Medioevo Romanzo XV (2): 177-210, 1990.

SAPIR, Edward (1921/1954) A linguagem. Introdução ao estudo da fala. Rio de Janeiro: Instituto Nacional do Livro, trad. de J.Mattoso Câmara Jr.

SILVA, Augusto Soares da (1997). A Linguística cognitiva. Uma breve introdução a um novo paradigma em linguística. Revista Portuguesa de Humanidades, vol. I (1-2), 59-101, 1997.

SILVA, Augusto Soares da (1999). A Semântica de deixar. Uma contribuição para a abordagem cognitiva em semântica lexical. Lisboa: Fundação Calouste Gulbenkian / Fundação para a Ciência e a Tecnologia.

TARALLO, Fernando (1984). A Fênix finalmente renascida. Boletim da ABRALIN 6: 95-103, 1984.

TORRES MORAIS, Maria Aparecida C. / ANDRADE, Maria Lúcia C.V.O (Orgs. 2009) História do português paulista. Série estudos, vol. 2. Campinas: Setor de Publicações / Fapesp.

WALDROP, M. Mitchell (1993) Complexity. The emerging science at the edge of order and chaos. New York: A Touchtone book.

WEINREICH, Uriel / LABOV, William / HERZOG, Marvin I. (1975) Empirical foundations for a theory of language change. Em: W.P. Lehman / Y. Malkiel (Eds. 1975) Directions for bistorical linguistics. A symposium. Austin: University of Texas Press, $3^{\text {rd }}$. edition, pp. 95-188.

ZÁGARI, Mario Roberto Lobuglio (1988) Fonologia diacrônica do Português. Juiz de Fora: Editora da Universidade Federal de Juiz de Fora. 